\title{
SEA-LEVEL TRANSITIONING DUAL BELL NOZZLES
}

\author{
Ralf Stark $^{(1)}$, Chloé Génin ${ }^{(1)}$ \\ (1) German Aerospace Center (DLR), Langer Grund, D-74239 Lampoldshausen, Germany
}

KEYWORDS: nozzle flow, dual bell

\begin{abstract}
:
To evaluate the impact of sea-level transitioning dual bell nozzles on the payload mass delivered into geostationary transfer orbit by Ariane 5 ECA, a detailed study was conducted. For this purpose, a multitude of Vulcain 2 and Vulcain 2.1 nozzle extension contours were designed. The two variation parameters were the position of the wall inflection and the constant wall pressure of the nozzle extension. Considering these parameters an approved analytical method was applied to predict the impact of the dual bell nozzles on the payload mass. The payload gain into geostationary transfer orbit was evaluated to be up to $219 \mathrm{~kg}$.
\end{abstract}

\section{INTRODUCTION}

The configuration of launch vehicles changed in the last decades from tandem to parallel staging. Europe's Ariane 5 is the well-established representative of this launcher group. Its liquid propulsion main stage is surrounded by two solid rocket boosters

To ensure the reliable operation of the main stage engine during flight, it is ignited prior to the booster stages. Therefore, the engine operates during flight over a wide altitude range, from sea-level up to vacuum conditions.

As flow separation inside the main engine nozzle causes undesired side loads with an amplitude of up to several percent of the engine thrust [1], it has to be avoided during sea-level operation. This constraint limits the nozzle area ratio. But, as the ambient pressure decreases during ascent of the launcher, a higher nozzle area ratio without flow separation would be possible. This would enable a higher specific impulse, leading to an increase of payload mass.

The Ariane 5 main stage engine Vulcain 2 illustrates the limitation of the nozzle area ratio. For a better overall engine performance during ascent of the launcher, an altitude adaptive nozzle with a higher area ratio for altitude conditions would be promising. The dual bell nozzle is such a desirable nozzle concept [2]. The nozzle consists of two bell shaped nozzle parts, linked by an abrupt wall contour inflection (Fig. 1). The inflection enables a controlled flow separation with low side loads during sea-level operation. The second bell, or nozzle extension, is designed following a constant or slightly positive wall pressure gradient profile [2]. This design ensures an immediate transition to altitude mode operation, for an increased nozzle performance.

During ascent of a launcher the ambient pressure decreases and the nozzle pressure ratio (NPR, ratio of total over ambient pressure) increases [2]. When reaching a certain altitude, the flow suddenly attaches to the nozzle extension wall down to the exit plane and the transition to altitude mode takes place. Due to the further expansion of the nozzle flow, the vacuum performance of the engine with full flowing dual bell nozzle extension is increased compared to a conventional engine. Figure 2 illustrates the operation modes of the dual bell nozzle.

A nozzle with an abrupt change of the wall contour angle in the diverging portion was first introduced by Foster and Cowles [3] in 1949, as a possibility to induce a controlled flow separation. In 1967, Fischer [4] identified the potential of such a wall inflection for a one-step altitude adaption, resulting in an increased overall nozzle performance.

First tests with cold flow models where conducted in the early 1990's by Horn and Fisher [5], to verify the flow behaviour and the existence of two distinct operation modes. Within the report it is mentioned, that a not otherwise specified single stage to orbit space vehicle (SSTO), targeting low earth orbit (LEO) by using 3 space shuttle main engines (SSME), would benefit from a dual bell application. A potential payload gain of $12.1 \%$ is stated.

At that time, SSTO configurations considering dual bell nozzles were also of interest in Europe and Japan. Cold and hot flow nozzle tests were performed by Haidinger et al. [6], in cooperation with Keldysh Research Center.

Manski et al. [7] analyse a SSTO vehicle where the application of a dual bell could reduce the lift-off mass for $4.51 \%$. In Japan, Kumakawa et al. [8] and Kusaka et al. [9] conducted hot flow tests on dual bell nozzle flow. Miyazawa et al. [10] stated a specific impulse gain of $10 \mathrm{~s}$ for a SSTO vehicle to LEO, based on a LE-7A engine. 


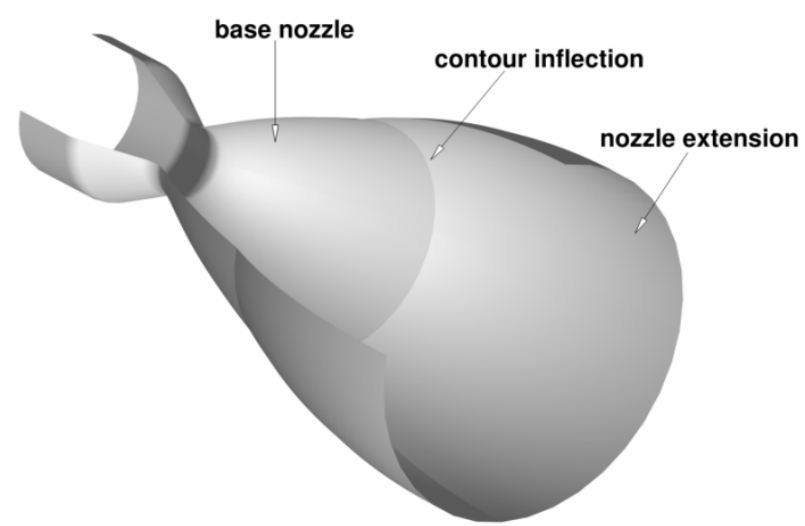

Figure 1. Dual bell nozzle concept [39]

Numerous system analysis were performed within FESTIP (Future European Space Transportation Investigation Programme). Immich and Caporicci $[11,12]$ as well as Hagemann et al. [13] analysed the FESTIP concept vehicle FSS-1 [14]. The studies revealed payload gains of $1235-1446 \mathrm{~kg}$, depending on the selected dual bell design. Hagemann et al. [15] pointed out that during sealevel operation mode of the dual bell a $3 \%$ performance loss has to be considered, caused by the nozzle extension drag.

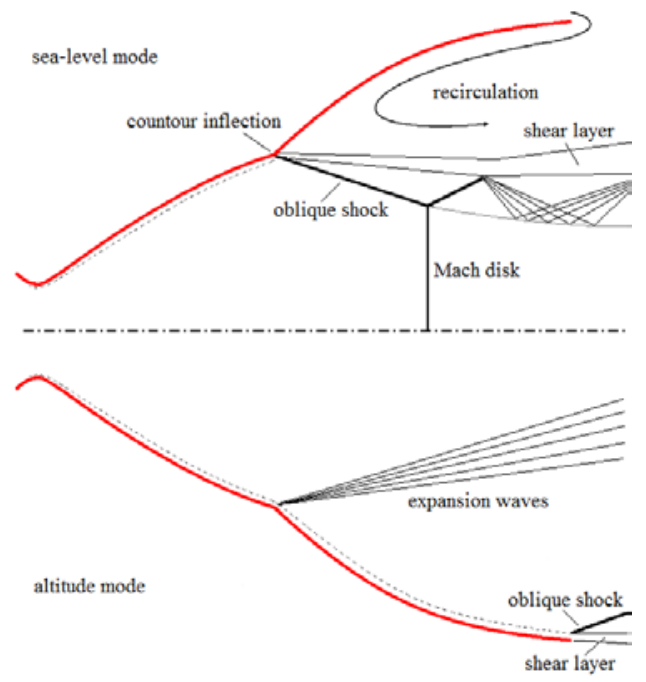

Figure 2. Sea-level mode (top) and altitude mode (bottom) [39]

In the following one and a half decades the work mainly focused on the dual bell flow behaviour itself. Experimentally, the performance [16-18], the transition/sneak transition [19-24], the hysteresis/buffeting effect $[18,21,25]$, the side loads [26], and the heat loads [27] were studied. Numerically, the transition/sneak transition $[24,28-$ $34]$, the hysteresis/buffeting effect $[30,35]$, the side loads [30, 33], the heat loads [24], and the jet oscillation [36] were studied as well. An overview of various altitude adaptive nozzle concepts is given by Hagemann et al. [37, 38].

The presented performance studies focused on SSTO applications, targeting low orbits. Currently and for the near future such systems are out of consideration. Nevertheless, the dual bell nozzle also offers a performance gain for today's operating launch systems. These successful commercial launch systems usually are targeting geostationary transfer orbit (GTO) and an assessment of the benefit of a dual bell nozzle application was missing.

\section{PRIOR STUDIES}

To study the impact of dual bell nozzles on the payload capacity of such a GTO launcher, a generic Ariane 5 ECA was defined and the conventional nozzle of its Vulcain 2 like main stage engine was replaced by a set of dual bell nozzles [39].

The generic Ariane 5 ECA launcher was modelled as a three stage rocket (see Tab. 1). The first ascent phase was in addition subdivided into a sea-level and an altitude part to reproduce the two dual bell operating modes.

Table 1, Generic Ariane 5 ECA

\begin{tabular}{ll} 
Parameter & Value \\
\hline payload & $9.7 \mathrm{t}$ \\
\hline main stage & EPC H 173 \\
lift-off mass & $188 \mathrm{t}$ \\
engine & Vulcain 2 \\
fuel type & LOX/LH2 \\
vacuum spec. impulse & $429 \mathrm{~s}$ \\
engine mass flow & $323 \mathrm{~kg} / \mathrm{s}$ \\
operating time & $540 \mathrm{~s}$ \\
\hline upper stage & ESC A \\
total mass & $19.2 \mathrm{t}$ \\
engine & $\mathrm{HM7B}$ \\
fuel type & LOX/LH2 \\
vacuum spec. impulse & $446 \mathrm{~s}$ \\
engine mass flow & $14.8 \mathrm{~kg} / \mathrm{s}$ \\
operating time & $970 \mathrm{~s}$ \\
\hline Booster stage & EAP P241 \\
Lift-off mass & $278 \mathrm{t}$ \\
engine & EAP P241 \\
fuel type & Al/HTPB/AP \\
vacuum spec. impulse & $275 \mathrm{~s}$ \\
operating time & $140 \mathrm{~s}$ \\
\hline
\end{tabular}

Using the characteristic values presented in Tab. 1 the velocity capacity of Ariane 5 ECA was calculated as a reference state to be approximately $12.3 \mathrm{~km} / \mathrm{s}$.

An analytical method was applied to evaluate the 
effect of different dual bell nozzle designs on the launcher's performance. The method is based on the Tsiolkovsky rocket equation and iterates the payload mass increment for a given specific impulse increase while considering the additional structure mass of the nozzle. The iteration is stopped if the reference velocity capacity is achieved. The calculations yield a nearly linear correlation between additional engine mass, specific impulse increase and payload gain:

$m_{p l+}[\mathrm{kg}]=-0.35 \cdot m_{V 2+}[\mathrm{kg}]+257 \cdot I_{s p, v a c+}[\%]$

The correlation can be applied to any sort of Vulcain 2 nozzle modification. It is illustrated over a wide range of input parameters in Fig. 3.

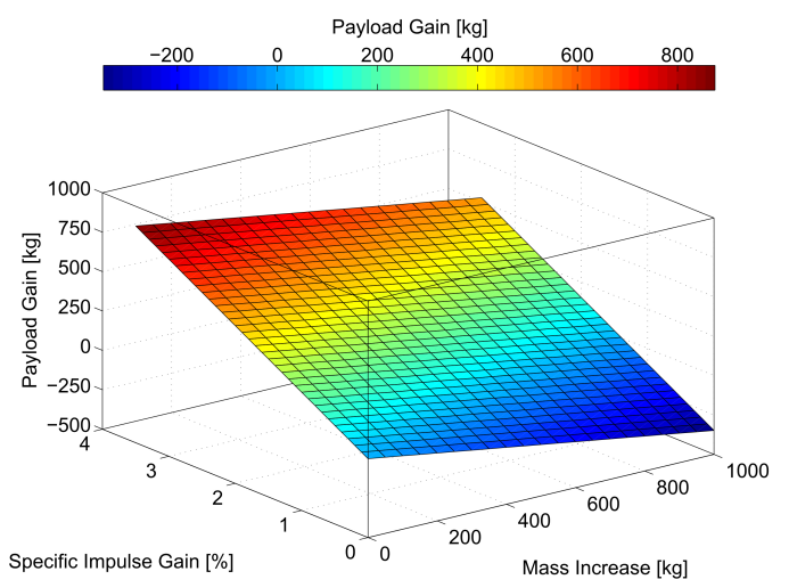

Figure 3. Payload gain by modified Vulcain 2 [39]

In addition, a detailed launch trajectory simulation was performed [39]. It validated the suitability of Eq. 1.

The study revealed a new group of dual bell nozzle extensions that has not been identified before. Its operation mode transition takes place during the transient engine start-up, i.e. $h_{\mathrm{tr}}=0 \mathrm{~km}$ and the dual bell nozzle extensions are already full flowing under sea-level conditions. Therefore, this group of nozzles was classified as sea-level transitioning dual bell (SLT-DB). This characteristic was a consequence of the specific geometrical design where the resulting constant wall pressure within the dual bell extension was below the exit wall pressure of Vulcain 2, but for an enlarged exit area ratio. Subsequently, this resulted in an increased vacuum impulse.

Although the group of SLT-DB achieves not the optimum payload gain within the prior study, it represents a set of possible nozzle modifications that can be easily applied with current manufacturing capacities.

\section{DESIGN OF DUAL BELL NOZZLE EXTENSIONS}

Based on the Vulcain 2 like main stage engine [39] several dual bell nozzle contours were designed.
For this purpose the original nozzle was shortened and considered as the base nozzle. Nine different wall inflection positions, corresponding to divergent nozzle lengths of 0.8 to $2.4 \mathrm{~m}$, with steps of $0.2 \mathrm{~m}$, were chosen. The configuration $L_{\text {inf }}=1.4 \mathrm{~m}$ corresponds to the position directly downstream the turbo pump exhaust gas (TEG) injection manifold. For each wall inflection position three extensions were designed, corresponding to transition pressure ratios $N P R_{\text {trans }}=p_{\mathrm{cc}} / p_{\mathrm{a}}$ of 82 , 100 , and 114 , respectively. The pressure ratio of 82 assures a safe and reliable transition during transient engine start-up. The pressure ratio of 114 delivers all hot gas expansion reserves given by Vulcain 2. The dual bell hysteresis, where $N P R_{\text {retrans }}<N P R_{\text {trans, }}$, will enable a stable transition. As an intermediate approach a transition pressure ratio of 100 was chosen.

The design of the extension contour was realized using a DLR in-house code based on the method of characteristics (MOC) [21]. The last point of the specified base nozzle marks the inflection point of the dual bell contour. Starting from the last rightrunning characteristic a Prandtl-Meyer expansion of the supersonic nozzle flow is calculated. As the intended extension wall pressure is reached, the expansion is stopped and the resulting inflection angle $\alpha_{\text {inf }}$ introduces an isobaric streamline that defines the extension contour.

The obtained nozzle section is a so called CP extension, yielding a constant wall pressure along the nozzle extension length. This type of dual bell nozzle extension has proven to ensure a fast and defined transition from one operation mode to the other [2]. Under full operation of Vulcain 2 the resulting extension wall pressures are 240, 280, and 352 mbar, respectively, where 352 mbar is the wall exit pressure of the reference nozzle. Table 2 gives the three transition pressure ratios, and the resulting extension wall pressures.

Table 2, Extension wall pressures

\begin{tabular}{ccc}
$\begin{array}{c}N P R_{\text {trans }} \\
\left(p_{\mathrm{cc}}, / p_{\mathrm{a}}\right)\end{array}$ & $\begin{array}{c}p_{\text {wext }}, \text { mbar } \\
\left(p_{\mathrm{cc}},=115.5 \text { bar }\right)\end{array}$ & Performance \\
\hline 114 & 240 & high \\
100 & 280 & intermediate \\
82 & 352 & safe \\
\hline
\end{tabular}

Two constraints were made. The first was based on the wall angle, i.e. the angle between the isobaric contour extension and the nozzle centre line. The design process was stopped if the angle reached 5.5 degrees. This value corresponds to the Vulcain 2 wall exit angle and it limits the length of the dual bell nozzle extension.

The second constraint is given by the nozzle exit area ratio $\varepsilon_{\mathrm{e}}=A_{\mathrm{e}} / A_{\mathrm{th}}$, that should not exceed a value of 100 , due to existing guiding tubes [39]. 
Figure 4 displays the designed SLT-DB contours for different wall inflection positions and a transition pressure ratio of $N P R_{\text {trans }}=114$. Figure 5 illustrates as an example the three studied dual contours starting at a nozzle length of $L_{\text {inf }}=1.8 \mathrm{~m}$.

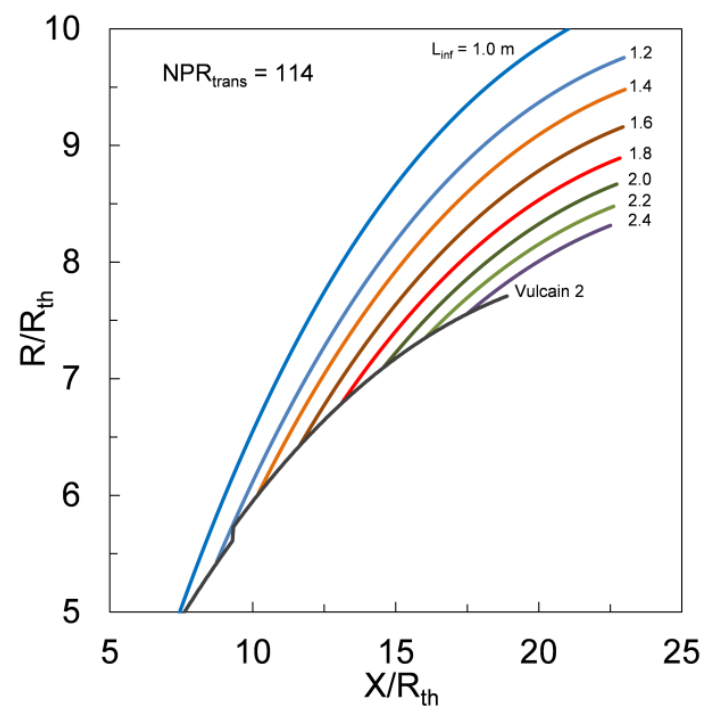

Figure 4. Dual bell contours for transition pressure ratio $N P R_{\text {trans }}=114$, starting at various wall positions

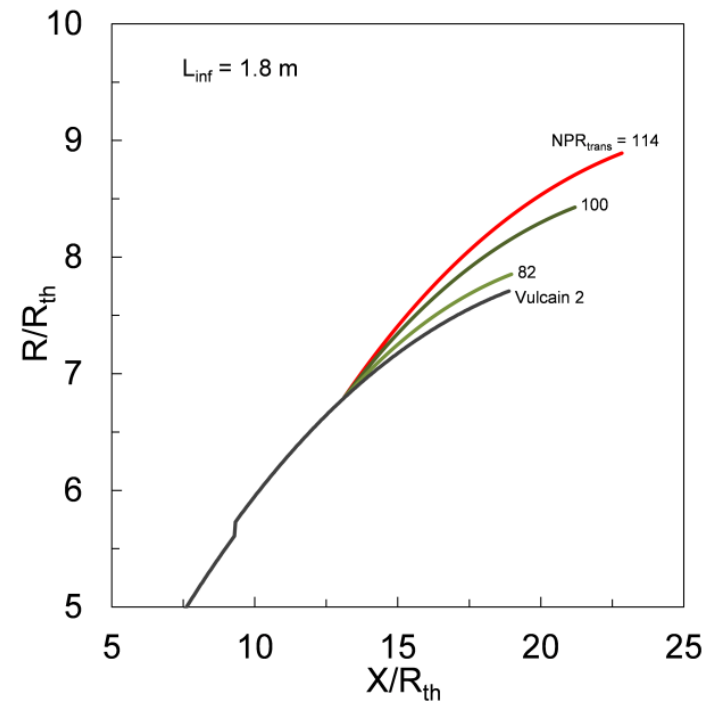

Figure 5. Dual bell contours starting at wall inflection position $L_{\text {inf }}=1.8 \mathrm{~m}$, for different transition ratios

The flow conditions in the generated contours, e.g. the wall pressure, and the specific impulse for altitude conditions, were calculated applying a similar method based on the MOC.

The resulting characteristic parameters are listed in Table 3. The designation of the different nozzles is a combination of the wall inflection position $L_{\text {inf }}$ and the transition pressure ration $N P R_{\text {trans }}$. For example L1.8-114 indicates a dual bell nozzle extension beginning at a divergent length of $L_{\text {inf }}=1.8 \mathrm{~m}$, with a transition pressure ratio of $N P R_{\text {trans }}=114$.

The redesigned Vulcain 2 reference impulse, marginally differs from the literature data given in Tab. 1. But for the study, the percentage impulse increase is of importance.

\section{ESTIMATION OF PAYLOAD GAIN}

To determine the potential payload gain using Eq. ${ }^{\circ} 1$, the nozzle mass increment is needed. The Vulcain 2 reference nozzle mass was determined in [39] to be $461 \mathrm{~kg}$. For this purpose the nozzle was subdivided in five sections (see Fig. 6). The mass of the interface ring and the TEG manifold were considered as constant values. For the base nozzle, the upper and the lower part of the film cooled extension a mass per nozzle surface area was assigned.

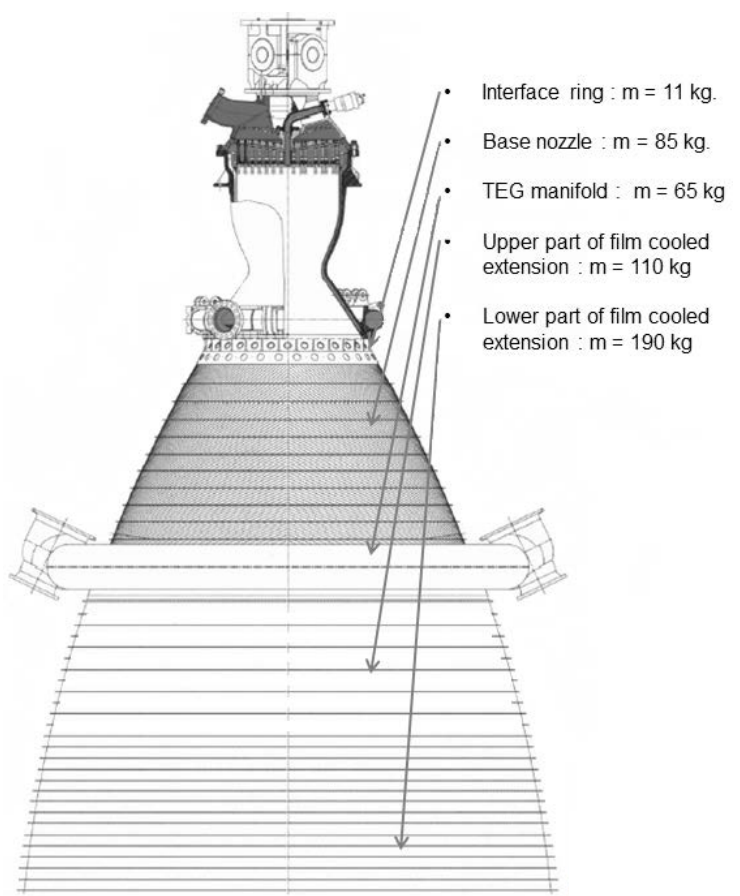

Figure 6. Estimated Vulcain 2 nozzle mass [39]

This approach was also used within the presented study, and in addition, the mass of a completely dump cooled sandwich nozzle, passing on film cooling, was calculated. This version is indicated Vulcain 2.1. Its base nozzle part was estimated to share the same mass per surface ratio as the reinforced Vulcain 2 base nozzle. This estimation relies on an outer jacket thickness of $3 \mathrm{~mm}$ [40]. Starting at an area ratio of approximately 20, additional stiffener rings are considered, increasing the mass per surface ratio in the range of $45 \%$. Assuming an identical nozzle contour, the Vulcain 2.1 reference nozzle mass can be estimated to be $393 \mathrm{~kg}$. But, it has to be considered that the two TEG pipes do have to be elongated, causing an additional mass of approximately $45 \mathrm{~kg}$.

For the mass calculation of the dual bell nozzle extensions the same method and material were applied. The resulting nozzle masses and payload gains are listed in Tab. 4.

\section{RESULTS AND DISCUSSION}

The payload gain that can be achieved by replacing the film cooled Vulcain 2 nozzle section with a SLT-DB is presented in Fig. 7. It appears 
that the maximum payload gain of $219 \mathrm{~kg}$ is achieved with the high performance configuration L1.8-114. Its length is extended about $0.54 \mathrm{~m}$ and its diameter increases about $0.4 \mathrm{~m}$.

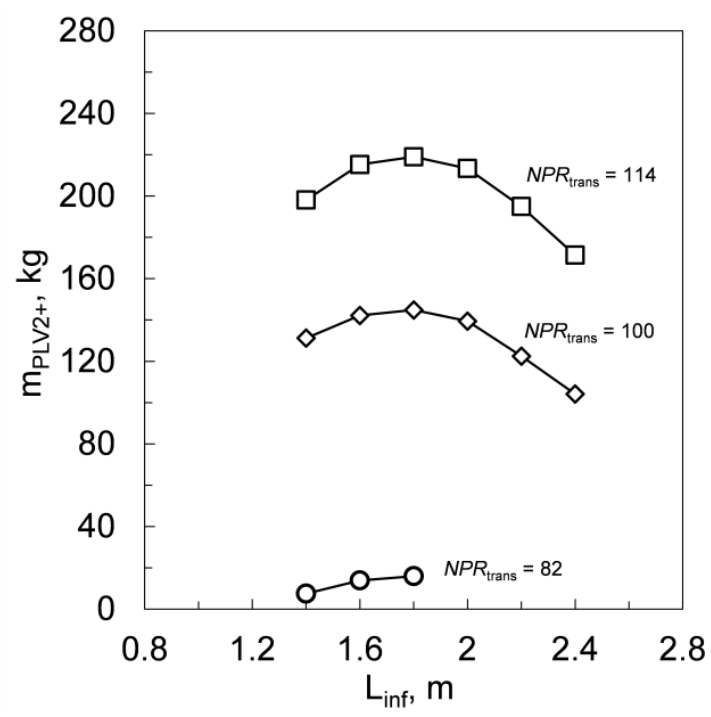

Figure 7. Payload gain Vulcain 2

The generation of the performance gain is illustrated in Fig. 8. Given are the nozzle contours and related wall pressures of the reference nozzle and configuration L1.8-114, as a function of the nozzle area ratio $A / A_{\text {th }}$. In this way, the thrust can be determined graphical. Initially, the SLT-DB causes thrust losses $\left(\Delta F_{1}\right)$ as the hot gas is expanded towards a lower constant value of 240 mbar. But, this loss is more than compensated by the additional thrust $\left(\Delta F_{2}\right)$ that is gained due to the additional nozzle surface area. In total a performance gain is achieved.

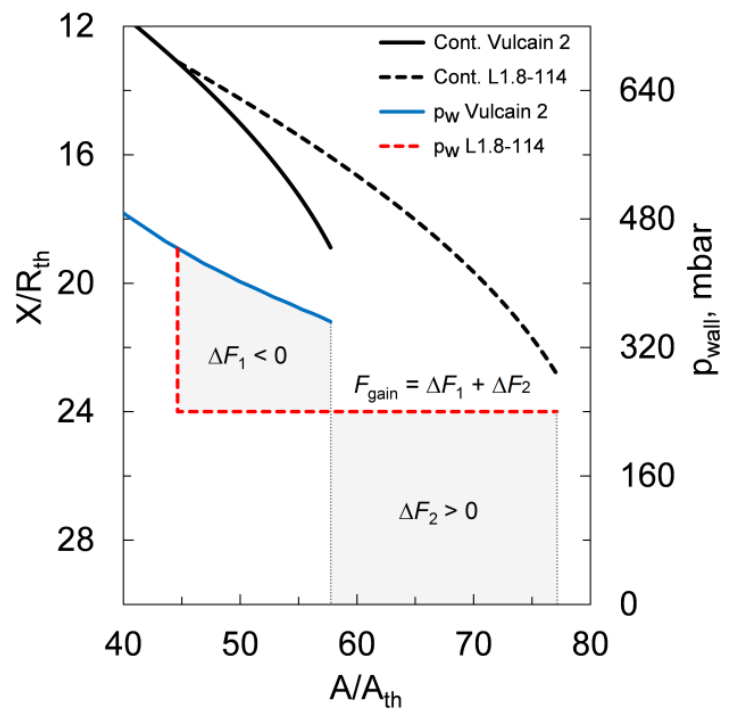

Figure 7. Thrust gain L1.8-114 $\left(p_{c c}=115.5\right.$ bar $)$

For the safe transition pressure ratio $N P R_{\text {trans }}=82$ only three SLT-DB were considered, as for inflection positions $L_{\text {inf }}>1.8 \mathrm{~m}$ the inflection angle $\alpha_{\text {inf }}$ is to small and the additional flow expansion is negligible. This set of nozzles achieves nearly no payload gain. The thrust generation of configuration L1.8-82 is shown in Fig. 9. The additional surface area is too small for a distinct thrust gain. Nevertheless, this set of nozzles offers, due to its contour inflection, the possibility of stabilized flow separation under reduced combustion chamber pressure conditions, with moderate side loads.

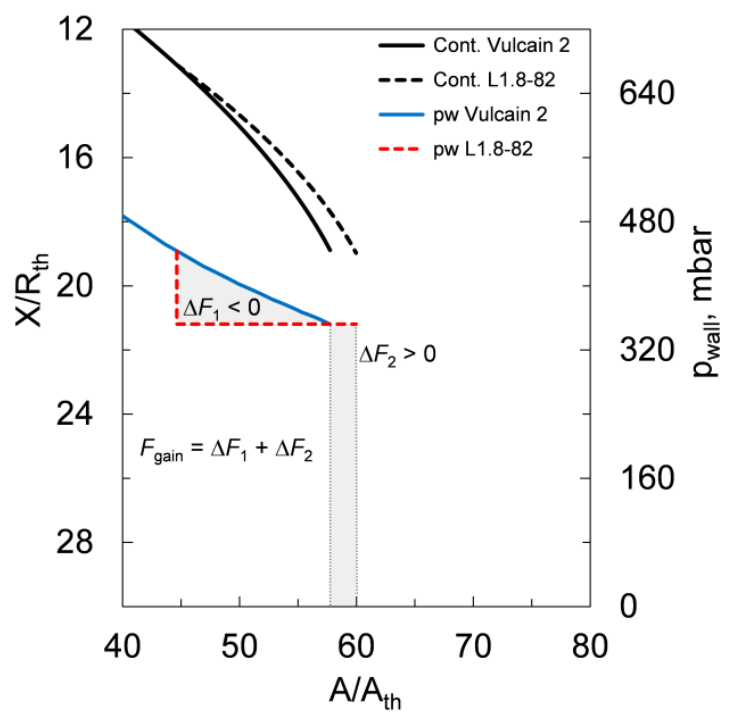

Figure 8. Thrust gain L1.8-82 $\left(p_{c c}=115.5\right.$ bar $)$

The intermediate transition pressure ratio of $N P R_{\text {trans }}=100$ reveals a set of SLT-DB nozzles that offers a payload gain of more than $100 \mathrm{~kg}$. Its lengths and exit diameters (see Tab. 3) are in the range of the original Vulcain 2 design, before the nozzle was shortened.

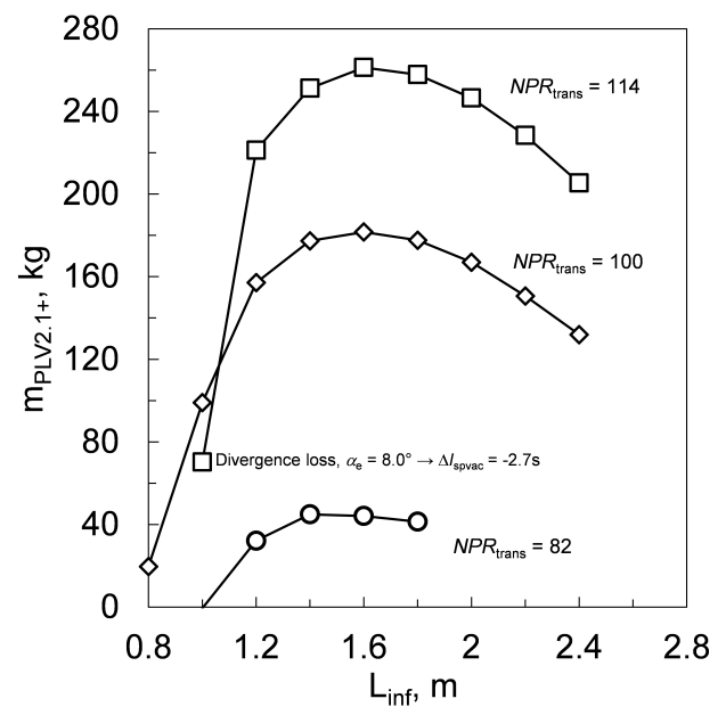

Figure 9. Payload gain Vulcain 2.1

Figure 9 illustrates the calculated performance gain of the alternative Vulcain 2.1 design. The characteristics are comparable and the difference 
in performance is mainly caused by different nozzle masses. A maximum payload gain of 261 $\mathrm{kg}$ was obtained.

As the wall inflection position $L_{\text {inf }}$ of the dumped cooled nozzle is not restricted by a TEG position, additional SLT-DB nozzle configurations were studied. Here, configuration L1.0-114 is striking. Its performance is below the configuration L1.0-100. As the nozzle exit area ratio was restricted to be below $\varepsilon_{\mathrm{e}} \leq 100$ the obtained wall exit angle $\left(\alpha_{\mathrm{e}}=8^{\circ}\right)$ of L1.0-114 causes a divergence loss of $\Delta l_{\mathrm{sp}}=-2.7 \mathrm{~s}$, resulting in the performance decrease.

In addition, the comparison of the two reference nozzles, presented in Tab.4, points out that switching from a film cooled nozzle extension to a dumped cooled sandwich nozzle seems not to offer a remarkable payload gain.

\section{CONCLUSION}

The study reveals that the application of a SLT-DB has the potential to increase the Ariane 5 ECA payload up to $10 \mathrm{t}$.

The concept is simple, easy to implement and has a retrofit capacity. As the operation mode transition takes place during transient engine start-up no concept qualification under altitude conditions becomes necessary. The wall inflection still offers a controlled flow separation position if reduced thrust operations are of future interest.

\section{REFERENCES}

1. Stark, R. (2010), Beitrag zum Verständnis der Strömungsablösung in Raketendüsen (Contribution to the Understanding of Flow Separation in Rocket Nozzles), Ph.D. Thesis (in German), RWTH Aachen, Germany.

2. Génin, C. (2010), Experimental Study of Flow Behavior and Thermal Loads in Dual Bell Nozzles,' Ph.D. Thesis, Université de Valenciennes, France.

3. Foster, C. and Cowles, F. (1949), Experimental Study of Gas-Flow Separation in Overexpanded Exhaust Nozzles for Rocket Motors, Jet Propulsion Laboratory, Progress Report 4-103.

4. Fischer, E. (1967), Nozzle Construction, US Patent, 3,352,495.

5. Horn, M. and Fisher, S. (1994), Dual-Bell Altitude Compensating Nozzle, Rocketdyne Division, NASA-CR-194719.

6. Haidinger, F., Goergen, J. and Haeseler, D. (1998), Experimental and Analytical Design Verification of the Dual-Bell Concept, 34th AIAA Joint Propulsion Conference, 17-18th of July, Huntsville, AL, AIAA 98-3368.

7. Manski, D., Hagemann, G., Frey, M. and Frenken, G. (1998), Optimisation of Dual Mode Rocket Engine Nozzles for SSTO
Vehicles, 49th International Astronautical Congress, 9.28.-10.02, Melbourne, Australia, IAF-98-S3.08.

8. Kumakawa, A., Tamura, H., Niino, M., Nosaka, M., Yamada, H., Kanmuri, A., Konno, A. and Atsumi, M. (1999), Propulsion Research for Rocket SSTOS at NAL/KRC, 35th AIAA Joint Propulsion Conference, 20-24th of June, Los Angeles, CA, AIAA 99-2337.

9. Kusaka, K., Kumakawa, A., Niino, M., Konno, A. and Atsumi, M. (2000), Experimental Study on Extendible and Dual-Bell Nozzles under High Altitude Conditions, 36th AIAA Joint Propulsion Conference, 16-19th of July, Huntsville, AL, AIAA 2000-3303.

10. Miyazawa, M., Takeuchi, S. and Takahashi, M. (2002), Flight Performance of Dual-Bell Nozzles, 40th AIAA Aerospace Sciences Meeting I\& Exhibit, 14-17th of January, Reno, NV, AIAA 2002-686.

11. Immich, H. and Caporicci, M. (1996), FESTIP Technology Developments in Liquid Rocket Propulsion for Reusable Launch Vehicles, 32nd AIAA Joint Propulsion Conference, 1-3rd of July, Lake Buena Vista, FL, AIAA 96-3113.

12. Immich, H. and Caporicci, M. (1997), Status of the FESTIP Rocket Propulsion Technology Programme, 33rd AIAA Joint Propulsion Conference, 6-9th of July, Seattle, WA, AIAA97-3311.

13. Hagemann, G., Terhardt, M., Haeseler, D. and Frey, M. (2000), Experimental and Analytical Design Verification of the Dual-Bell Concept, 36th AIAA Joint Propulsion Conference, 1619th of July, Huntsville, AL, AIAA 2000-3778.

14. Kuczera, H., Sacher, P. and Dujarric, C. (1996), FESTIP System Study - An overview, 7th AIAA Space Plane and Hypersonic Systems and Technology Conference, 1822th of November, Norfolk, VA, A9710801, doi 10.2514/6.1996-6004.

15. Hagemann, G., Frey, M. and Manski, D. (1997), A Critical Assessment of Dual-Bell Nozzles, 33rd AIAA Joint Propulsion Conference, 6-9th of July, Seattle, WA, AIAA 97-3299.

16. Dumnov, G., Nikulin, G. and Ponomarev, N. (1996), Advanced Rocket Engine Nozzles, 32nd AIAA Joint Propulsion Conference, 1-3rd of July, Lake Buena Vista, FL, AIAA 96-3221.

17. Kimura, T., Niu, K., Yonezawa, K., Tsujimoto, Y. and Ishizaka, K. (2009), Experimental and Analytical Study for Design of Dual-Bell Nozzles, 45th AIAA Joint Propulsion Conference, 2nd-5th August, Denver, CO, AIAA 2009-5149.

18. Nürnberger-Génin, C. and Stark, R. (2009), 
Flow Transition in Dual Bell Nozzles, Shock Waves, Vol. 19, No. 3, pp 265-270.

19. Tomita, T., Takahashi, M., Sasaki, M. and Tamura, H. (2006), Investigation on Characteristics of Conventional-Nozzle-Based Altitude Compensating Nozzles by Cold-Flow Tests, 42nd AIAA Joint Propulsion Conference, 9-12th July, Sacramento, CA, AIAA 2006-4375.

20. Reijasse, P., Coponet, D., Luyssen, J-M., Bar, V., Palerm, S., Oswald, J., Amouroux, F., Robinet, J-C. and Kuszla, P., Wall Pressure and Thrust of a Dual Bell Nozzle in a Cold Gas Facility, 3rd European Conference for Aerospace Sciences (EUCASS), 6-9th July, Versailles, France.

21. Nürnberger-Génin, C. and Stark, R. (2010), Experimental Study on Flow Transition in Dual Bell Nozzles, Journal of Propulsion and Power, Vol. 26, No. 3, pp 497-502.

22. Verma, S., Stark, R., Nürnberger-Génin, C. and Haidn, O. (2010), Cold-Gas Experiments to Study the Flow Separation Characteristics of a Dual-Bell Nozzle during its Transition Modes, Shock Waves, Vol. 20, No. 3, pp 191203.

23. Génin, C. and Stark, R. (2012), Influence of the Test Environment on the Transition of DualBell Nozzles, 28th ISTS Special Issue, Vol. 10, pp 49-53.

24. Génin, C., Stark, R., Haidn, O., Quering, K. and Frey, M. (2013), Experimental and Numerical Study of Dual Bell Nozzle Flow, Progress in Flight Physics, Vol. 5, pp 363-376.

25. Verma, S., Stark, R. and Haidn, O. (2014), Effect of Ambient Pressure Fluctuations on Dual-Bell Transition Behavior, Journal of Propulsion and Power, Vol. 30, No. 5, pp 11921198.

26. Génin, C. and Stark, R. (2011), Side Loads in Subscale Dual Bell Nozzles, Journal of Propulsion and Power, Vol. 27, No. 4, pp 828837.

27. Génin, C., Gernoth, A. and Stark, R. (2013), Experimental and Numerical Study of Heat Flux in Dual Bell Nozzles, Journal of Propulsion and Power, Vol. 29, No. 1, pp 2126.

28. Onofri, M., Nasuti, F. and Martelli, E. (2002), Analysis of the Transition Process in Dual-Bell Nozzles, 4th International Conference on Launcher Technology, 3rd-6th December, Liège, Belgium, Proceedings.

29. Wong, H. and Schwane, R. (2002), Numerical Investigation of Transition in Flow Separation in a Dual-Bell Nozzle, 4th International Conference on Launcher Technology, 3rd-6th
December, Liège, Belgium, Proceedings.

30. Karl, S. and Hannemann, K. (2005), Numerical Investigation of Transient Flow Phenomena in Dual-Bell Nozzles, 6th International Symposium on Launcher Technologies, 811th November, Munich, Germany, Proceedings.

31. Martelli, E., Nasuti, F. and Onofri, M. (2005), Effect of the Wall Shape and Real Gas Properties on Dual-Bell Nozzle Flowfield, 41st AIAA Joint Propulsion Conference, 10-13th July, Tuscon, AZ, AIAA 2005-3943.

32. Nasuti, F., Onofri, M. and Martelli, E. (2005), Role of Wall Shape on the Transition in Axisymmetric Dual-Bell Nozzles, Journal of Propulsion and Power, Vol. 21, No. 2, pp 243250.

33. Martelli, E., Nasuti, F. and Onofri, M. (2007), Numerical Parametric Analysis of Dual-Bell Nozzle Flows, AIAA Journal, Vol. 45, No. 3, pp 640-650.

34. Martelli, E., Nasuti, F. and Onofri, M. (2009), Film Cooling Effect on Dual-Bell Nozzle Flow Transition, 45th AIAA Joint Propulsion Conference, 2nd-5th August, Denver, CO, AIAA 2009-4953.

35. Perigo, D., Schwane, R. and Wong, H. (2003), A Numerical Comparison of the Flow in Conventional and Dual-Bell Nozzles in the Presence of an Unsteady External Pressure Environment, 39th AIAA Joint Propulsion Conference, 21st-23rd July, Huntsville, AL, AIAA 2003-4731.

36. Proschanka, D., Koichi, Y., Tsukuda, H., Araka, K., Tsujimoto, Y., Kimura, T. and Yokota, K. (2012), Jet Oscillation at Low-Altitude Operation Mode in Dual-Bell Nozzle, Journal of Propulsion and Power, Vol. 28, No. 5, pp 1071-1080.

37. Hagemann, G., Immich, H., Van Nguyen, T. and Dumnov, G. (1998), Advanced Rocket Nozzles, Journal of Propulsion and Power, Vol. 14, No. 5, pp 620-634.

38. Hagemann, G., Immich, H., Nguyen, T. and Dumnov, G. (2004), Rocket Engine Nozzle Concepts, Progress in Astronautics and Aeronautics, Liquid Rocket Thrust Chambers: Aspects of Modeling, Analysis, and Design, edited by Yang V. et al., Vol. 200, Chapter 12, pp 437-467.

39. Stark, R., Génin, C., Schneider, D. and Fromm, C. (2016), Ariane 5 Performance Optimization using Dual Bell Nozzle Extension, Journal of Spacecrafts and Rockets, in print.

40. Sandwich Nozzles, Volvo Aero, Fact Sheet 150-T-506-0506-EN-1-PROFIL. 
Table 3, Characteristic parameters and performance gain

\begin{tabular}{lccccccccc} 
Type & $\mathrm{L}_{\text {inf }}(\mathrm{mm})$ & $\varepsilon_{\text {inf }}$ & $\alpha_{\text {inf }}$ & $\mathrm{L}_{\text {tot }}(\mathrm{mm})$ & $\varepsilon_{\mathrm{e}}$ & $\mathrm{F}_{\mathrm{vac}}(\mathrm{kN})$ & $\mathrm{I}_{\text {spvac }}(\mathrm{s})$ & $\mathrm{I}_{\text {sp+ }}(\mathrm{s})$ & $\mathrm{I}_{\text {sp+ }}(\%)$ \\
\hline Vulcain 2 & & & & 2593 & 58 & 1346 & 424.8 & 0.00 & \\
\hline L0.8-82 & 800 & 18.04 & 13.53 & 2705 & 81.39 & 1345 & 424.5 & -0.35 & -0.08 \\
L1.0-82 & 1000 & 23.71 & 9.91 & 2625 & 72.94 & 1346 & 424.8 & -0.03 & -0.01 \\
L1.2-82 & 1200 & 29.37 & 7.30 & 2625 & 67.74 & 1348 & 425.3 & 0.43 & 0.10 \\
L1.4-82 & 1400 & 34.82 & 5.36 & 2620 & 64.16 & 1348 & 425.4 & 0.56 & 0.13 \\
L1.6-82 & 1600 & 39.94 & 3.85 & 2610 & 61.64 & 1348 & 425.3 & 0.51 & 0.12 \\
L1.8-82 & 1800 & 44.62 & 2.70 & 2605 & 59.97 & 1347 & 425.2 & 0.40 & 0.09 \\
\hline L0.8-100 & 800 & 18.04 & 16.17 & 2800 & 100.09 & 1349 & 425.7 & 0.90 & 0.21 \\
L1.0-100 & 1000 & 23.71 & 12.55 & 2915 & 89.99 & 1353 & 427.1 & 2.23 & 0.52 \\
L1.2-100 & 1200 & 29.37 & 9.94 & 2940 & 86.08 & 1356 & 427.9 & 3.10 & 0.73 \\
L1.4-100 & 1400 & 34.82 & 7.99 & 2935 & 77.02 & 1357 & 428.2 & 3.32 & 0.78 \\
L1.6-100 & 1600 & 39.94 & 6.49 & 2920 & 72.55 & 1357 & 428.1 & 3.29 & 0.77 \\
L1.8-100 & 1800 & 44.62 & 5.34 & 2910 & 69.19 & 1356 & 428.0 & 3.15 & 0.74 \\
L2.0-100 & 2000 & 48.79 & 4.42 & 2900 & 66.54 & 1355 & 427.7 & 2.91 & 0.68 \\
L2.2-100 & 2200 & 52.40 & 3.68 & 2885 & 64.37 & 1354 & 427.4 & 2.58 & 0.61 \\
L2.4-100 & 2400 & 55.41 & 3.08 & 2875 & 62.70 & 1353 & 427.1 & 2.24 & 0.53 \\
\hline L0.8-114 & 800 & 18.04 & 17.90 & 2420 & 100.04 & 1330 & 419.6 & -5.23 & -1.23 \\
L1.0-114 & 1000 & 23.71 & 14.28 & 2890 & 100.03 & 1352 & 426.6 & 1.80 & 0.42 \\
L1.2-114 & 1200 & 29.37 & 11.67 & 3155 & 95.12 & 1361 & 429.5 & 4.63 & 1.09 \\
L1.4-114 & 1400 & 34.82 & 9.72 & 3160 & 87.80 & 1362 & 429.8 & 4.99 & 1.17 \\
L1.6-114 & 1600 & 39.94 & 8.22 & 3150 & 81.89 & 1362 & 429.9 & 5.03 & 1.18 \\
L1.8-114 & 1800 & 44.62 & 7.07 & 3135 & 77.12 & 1362 & 429.7 & 4.87 & 1.15 \\
L2.0-114 & 2000 & 48.79 & 6.15 & 3120 & 73.26 & 1361 & 429.4 & 4.59 & 1.08 \\
L2.2-114 & 2200 & 52.40 & 5.41 & 3105 & 70.03 & 1360 & 429.1 & 4.22 & 0.99 \\
L2.4-114 & 2400 & 55.41 & 4.81 & 3090 & 67.32 & 1358 & 428.6 & 3.77 & 0.89 \\
\hline
\end{tabular}


Table 4, Nozzle mass and payload gain

\begin{tabular}{|c|c|c|c|c|c|c|c|}
\hline \multirow[b]{2}{*}{ Type } & \multirow[b]{2}{*}{$\mathrm{I}_{\mathrm{sp}+}(\%)$} & \multicolumn{3}{|c|}{ Vulcain 2} & \multicolumn{3}{|c|}{ Vulcain 2.1} \\
\hline & & $\mathrm{m}_{\text {NozzV2 }}(\mathrm{kg})$ & $\mathrm{m}_{\mathrm{NozzV} 2+}(\mathrm{kg})$ & $\mathrm{m}_{\mathrm{PLV} 2+}(\mathrm{kg})$ & $\mathrm{m}_{\text {NozzV2.1 }}(\mathrm{kg})$ & $\mathrm{m}_{\text {NozzV2.1+ }}(\mathrm{kg})$ & $m_{P L V 2.1+}(\mathrm{kg})$ \\
\hline w/o DB & & 462 & & & 393 & -24 & 8 \\
\hline L0.8-82 & -0.08 & & & & 479 & 44 & -36 \\
\hline L1.0-82 & -0.01 & & & & 433 & -4 & 0 \\
\hline L1.2-82 & 0.10 & & & & 419 & -18 & 32 \\
\hline L1.4-82 & 0.13 & 538 & 76 & 8 & 410 & -31 & 45 \\
\hline L1.6-82 & 0.12 & 510 & 48 & 14 & 402 & -38 & 44 \\
\hline L1.8-82 & 0.09 & 485 & 23 & 16 & 398 & -49 & 41 \\
\hline L0.8-100 & 0.21 & & & & 533 & 100 & 20 \\
\hline L1.0-100 & 0.52 & & & & 534 & 102 & 99 \\
\hline L1.2-100 & 0.73 & & & & 518 & 87 & 157 \\
\hline L1.4-100 & 0.78 & 661 & 199 & 131 & 502 & 67 & 177 \\
\hline L1.6-100 & 0.77 & 624 & 162 & 142 & 488 & 49 & 182 \\
\hline L1.8-100 & 0.74 & 592 & 130 & 145 & 479 & 36 & 178 \\
\hline L2.0-100 & 0.68 & 566 & 104 & 139 & 472 & 25 & 167 \\
\hline L2.2-100 & 0.61 & 557 & 96 & 122 & 465 & 15 & 151 \\
\hline L2.4-100 & 0.53 & 552 & 90 & 104 & 461 & 11 & 132 \\
\hline L0.8-114 & -1.23 & & & & 432 & -8 & -314 \\
\hline L1.0-114 & 0.42 & & & & 542 & 110 & 70 \\
\hline L1.2-114 & 1.09 & & & & 595 & 168 & 221 \\
\hline L1.4-114 & 1.17 & 759 & 297 & 198 & 576 & 145 & 251 \\
\hline L1.6-114 & 1.18 & 717 & 255 & 215 & 558 & 123 & 261 \\
\hline L1.8-114 & 1.15 & 678 & 216 & 219 & 543 & 105 & 258 \\
\hline L2.0-114 & 1.08 & 646 & 184 & 213 & 532 & 89 & 247 \\
\hline L2.2-114 & 0.99 & 634 & 172 & 195 & 523 & 77 & 228 \\
\hline L2.4-114 & 0.89 & 624 & 162 & 171 & 515 & 65 & 205 \\
\hline
\end{tabular}

